\title{
Status of Geometry Effects on Structural Nuclear Composite Properties
}

\author{
W.E. Windes \\ W.R. Lloyd \\ September 2005
}

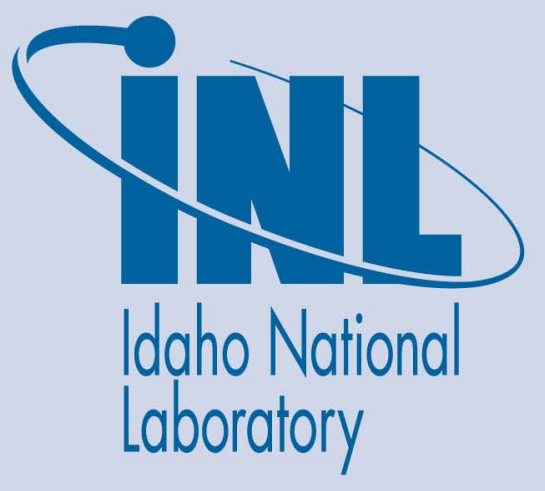

The INL is a U.S. Department of Energy National Laboratory operated by Battelle Energy Alliance 
INL/EXT-05-00756

\title{
Status of Geometry Effects on Structural Nuclear Composite Properties
}

\author{
W.E. Windes \\ W.R. Lloyd
}

September 2005

\begin{abstract}
Idaho National Laboratory
Idaho Falls, Idaho 83415
\end{abstract}

Prepared for the

U.S. Department of Energy

Office of Nuclear Energy

Under DOE Idaho Operations Office

Contract DE-AC07-05ID14517 


\begin{abstract}
Irradiation creep has been identified as a primary degradation mechanism for the structural ceramic composites being considered for control rod applications within the VHTR design. While standard sized (i.e. 150-mm long or longer) test specimens can be used for baseline non-irradiated thermal creep studies, very small, compact, tensile specimens will be required for the irradiated creep studies. Traditionally, it is standard practice to use small, representative test samples in place of full-size components for an irradiated study. However, a real problem exists for scale-up of composite materials. Unlike monolithic materials, these composites are engineered from two distinct materials using complicated infiltration techniques to provide full density and maximum mechanical properties. The material properties may be significantly affected when the component geometry or size is changed. It must be demonstrated that the smaller test samples used in an irradiated study will adequately represent larger composite tubes used for control rod applications. To accomplish this, two different test programs are being implemented to establish that small, flat test specimens are representative of the mechanical response for large, cylindrical composite tubes: a size effect study and a geometry effect study.
\end{abstract}




\section{CONTENTS}

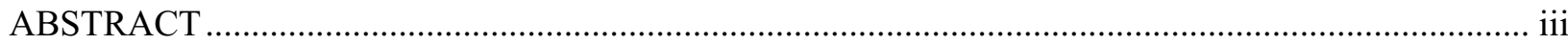

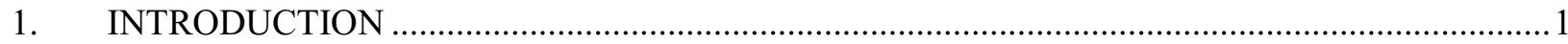

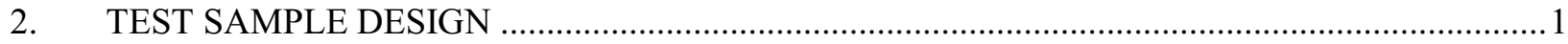

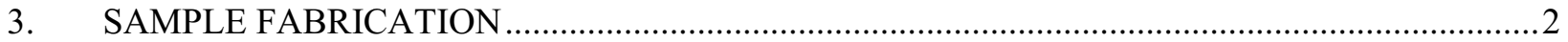

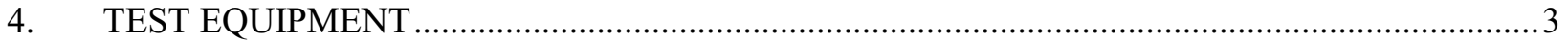

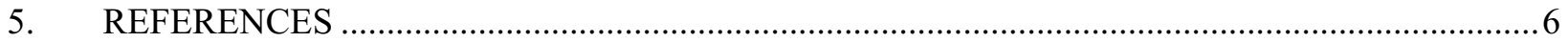

\section{FIGURES}

1. Schematic of a) tubular test samples and b) flat, "dog-bone" tensile test specimen. 3

2. Schematic illustrations of a) environmental chamber surrounding sample and grip assembly b) high temperature grips and extensometers with sample, and c) grip assembly inside cut-away environmental chamber (retort).

3. Typical environmental chamber housing required electronics, mechanical grips, and extensometers

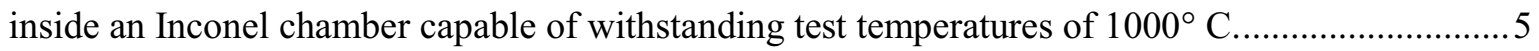

4. High temperature grip design for passive loading of tubular test specimen. ......................................6

\section{TABLES}

1. Anticipated operating parameters for composite control rods...........................................................

2. Fabrication parameters and test specimen dimensions for composite samples................................... 


\section{Status of Geometry Effects on Structural Nuclear Composite Properties}

\section{INTRODUCTION}

Extensive thermo-mechanical testing will be required to determine whether $\mathrm{SiC}_{\mathrm{f}} / \mathrm{SiC}$ or $\mathrm{C}_{\mathrm{f}} / \mathrm{C}$ ceramic composites are truly viable in a control rod cladding application. Since the temperatures within a VHTR core are anticipated to be extreme $\left(\sim 1600^{\circ} \mathrm{C}\right)$ thermal stability, or creep resistance, is recognized as a primary degradation mechanism over the lifetime of the reactor (up to 60 years). In addition, core components are expected to receive the largest flux levels with a corresponding total dose of $30 \mathrm{dpa}$ for these lifetime components. This requires that an extensive thermal and irradiation creep program be conducted upon these composite systems to determine the structural stability over the reactor lifetime.

Irradiation creep has been identified as a primary degradation mechanism for the structural ceramic composites being considered for control rod applications within the VHTR design. ${ }^{1}$ While standard sized (i.e. 150-mm long or larger) test specimens can be used for baseline non-irradiated thermal creep studies very small, compact tensile specimens will be required for the irradiated creep studies.

Traditionally, it is standard practice to use small, representative test samples in place of full-size components. However, a real problem exists for scale-up of composite materials. Unlike monolithic materials these are composites engineered from two distinct materials using complicated infiltration techniques to provide full density and maximum mechanical properties. The material properties may be significantly affected when the component geometry or size is changed. This is a major consideration since small sample sizes and more suitable geometries are required for test samples especially for irradiated sample studies where the material must be placed within the limited space of a reactor. It must be demonstrated that the smaller test samples adequately represent the true response of larger composite tubes used for control rod applications.

To accomplish this, two different test programs are being implemented to establish that small, flat test specimen are representative of the mechanical response for large, cylindrical composite tubes; a size effect study and a geometry effect study.

\section{TEST SAMPLE DESIGN}

Both non-irradiated and irradiated high temperature mechanical testing must be performed to ascertain the response for these two ceramic composite systems. While standardized sample test sizes and tubular geometry can be used for non-irradiated baseline testing irradiated studies will require miniaturized samples that can be easily accommodated within the restricted space of a reactor. To fit into any nuclear reactor, test samples much smaller than the actual control rod diameters $(\sim 100-\mathrm{mm}$ dia. $)$ will be required. In addition, to further reduce the test sample volume and provide a larger number of irradiated samples, flat, "dog-bone"-shaped tensile specimens are considered to be an optimal geometry for test specimens. However, before these smaller, flat tensile specimens can be utilized it needs to be established that they are truly representative of large tubes, which would be used for the control rods.

Two different test programs are required to establish that small, flat test specimen are representative of the mechanical response for large, cylindrical composite tubes; a size effect study and a geometry effect study. These studies will be performed on non-irradiated test specimens with similar fiber preform architectures and infiltration techniques. 
Geometry effects: Small tubular specimens approximately 125-mm long x 10-mm diameter have been fabricated along with large $254-\mathrm{mm} \times 76-\mathrm{mm}$ flat plates for future testing. ${ }^{2}$ Flat tensile specimens with similar outer dimensions as the tubular specimens will be machined from the flat plate stock. Both flat plate and tubular specimens will be compared and analyzed in "head-to-head" mechanical tests.

Size effects: Once the geometry effects have been accounted for, the effects resulting from sample size on the mechanical response will be investigated. The size effects study will be conducted with tubular samples only. Flat tensile specimens will not be used. A series of variable sized tubular samples will be fabricated for tensile testing. Sizes will range from $10-\mathrm{mm}$ dia. $-50-\mathrm{mm}$ dia. and may include a full-size (i.e. 100-mm) series of test specimens if deemed appropriate based upon the results from the smaller diameter testing.

\section{SAMPLE FABRICATION}

Test samples for the geometry effects study were designed and fabricated based upon the anticipated operating parameters for composites control rods, Table $1 .{ }^{3,4}$ Previous experience ${ }^{5}$ and the inservice conditions expected in the reactor were used to narrow the composite design parameters to a manageable list for each composite type.

Table 1. Anticipated operating parameters for composite control rods.

\begin{tabular}{|l|l|}
\hline \multicolumn{1}{|c|}{ Parameters } & \multicolumn{1}{c|}{ Assumed values } \\
\hline Control rod dimensions & \\
Diameter & $90-101-\mathrm{mm}$ \\
Thickness & $2-3 \mathrm{~mm}$ \\
Length (section) & $\sim 90 \mathrm{~mm}$ \\
Length (core length) & $\sim 10 \mathrm{~m}$ \\
\hline Static load & $3-5 \mathrm{MPa}$ \\
\hline Dynamic load (stuck rod) & $\sim 6-10 \mathrm{MPa}$ \\
\hline Operating temperatures & \\
Normal operation & $1250^{\circ} \mathrm{C}$ \\
Off-normal & $1600^{\circ} \mathrm{C}$ \\
Max. temp. gradient & $800^{\circ} \mathrm{C}-1250^{\circ} \mathrm{C}$ \\
\hline Expected dose & $0.5 \mathrm{dpa} / \mathrm{yr}(30 \mathrm{dpa}$ total $)$ \\
\hline Operating environment & $\mathrm{He}(\mathrm{min}$. impurities $)$ \\
\hline
\end{tabular}

Due to the relatively low operating stresses and lack of hermetic requirements it was decided that a simple $\pm 45^{\circ}$ bi-axial braiding architecture was sufficient for both composite fiber preforms. This greatly simplified the braiding process, reduced the amount of reinforcing fiber needed, and still provided sufficient strength to meet the in-service requirements. However, both the infiltration methods and materials used for each composite type were distinctly different. Test samples for both $\mathrm{SiC}_{\mathrm{f}} / \mathrm{SiC}$ and $\mathrm{C}_{\mathrm{f}} / \mathrm{C}$ composites are currently being fabricated. Details are given in Table 2. 
Table 2. Fabrication parameters and test specimen dimensions for composite samples.

$\mathrm{SiC}_{\mathrm{f}} / \mathrm{SiC}$ composites

Simple tube braid preform architecture

Hi Nicalon Type-S fibers

CVI (chemical vapor infiltration)

Beta-SiC

Multiple infiltration cycles

$\sim 85 \% \mathrm{TD}$

High temperature anneal between cycles

20 - 127-mm x 9.5-mm diameter tubes

$4-254 \times 76 \times 2.5-\mathrm{mm}$ thick plates

40 - non-Type $\mathrm{S}$ tubes for ASTM round robin testing (127-mm x 9.5-mm diameter)
$\mathrm{C}_{\mathrm{f}} / \mathrm{C}$ composites

Simple tube braid preform architecture

Mesophase pitch

Both fibers \& matrix material

Superior irradiation stability

Liquid infiltration

Fully graphitized @ $2500-3000{ }^{\circ} \mathrm{C}$

$\sim 91 \% \mathrm{TD}$

1 - full-sized prototype control rod section

5 - 100-mm diameter tubes

$3-30-\mathrm{cm} \times 30-\mathrm{cm} \times 2-\mathrm{mm}$ thick plates

The flat, dog-bone shaped tensile specimens will be machined from the larger flat plates. These flat specimens will be approximately the same size as the tubular specimens (i.e. same height and wall thickness), Figure 1. High temperature grips capable of being used for both tubular and flat tensile specimens are being designed, as discussed previously.

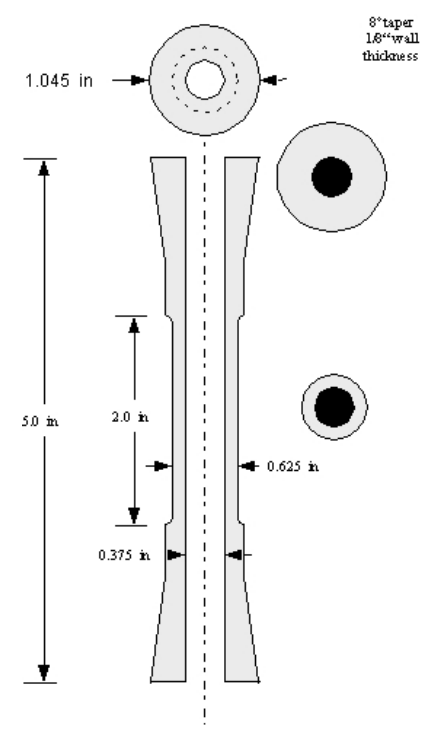

a.

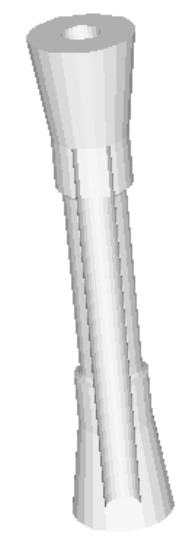

b.

Figure 1. Schematic of a) tubular test samples and b) flat, "dog-bone" tensile test specimen.

\section{TEST EQUIPMENT}

Room-temperature studies: Room temperature tensile tests of both tubular and flat plate specimens are primarily designed to investigate the geometry effects study. The quantitative geometry effects between the tubular and flat plate specimens will be determined using a series of head-to-head 
comparison tests between the flat "dog-bone" and tubular tensile specimens. These tests will be conducted both at the USA national laboratories and with our French collaborators as part of the international test standards development for structural ceramics in nuclear applications.

A round robin testing program including all USA labs (ORNL, INL, and PNNL) and the University of Bordeaux-France will be used to analyze the head-to-head comparison tests. In addition, ASTM methodology will be used to determine the appropriate number of tubular and flat plate specimens necessary to carry-out these round robin tests. Once the sample matrix has been established the participating laboratories will mechanically test the samples in tension using similar methods. The results will be fed back to the appropriate ASTM subcommittee (or working group) and analyzed. Experts from all labs must work within ASTM guidelines and methods to produce a defensible test matrix and testing procedures for these geometry effects studies.

High temperature load frames: While the majority of the geometry effects study will be conducted at room temperature some high temperature tensile tests will be conducted as well. Temperature ranges from $900{ }^{\circ} \mathrm{C}$ to $1600^{\circ} \mathrm{C}$ will provide a non-irradiated baseline of tensile strength, matrix-cracking stress, and creep data for both flat plate and tubular geometry specimens. The test results from both geometry types will be compared to ascertain the geometry effects on these composite structures at elevated temperatures.

Elevated temperature tests will be tested within high temperature load frames using vertical clamshell heaters and a static load. However, due to the anticipated service in the VHTR, the test frames will necessarily be outfitted with an environmental chamber allowing the samples to be tested at temperature in a He atmosphere, Figures 2 and 3.
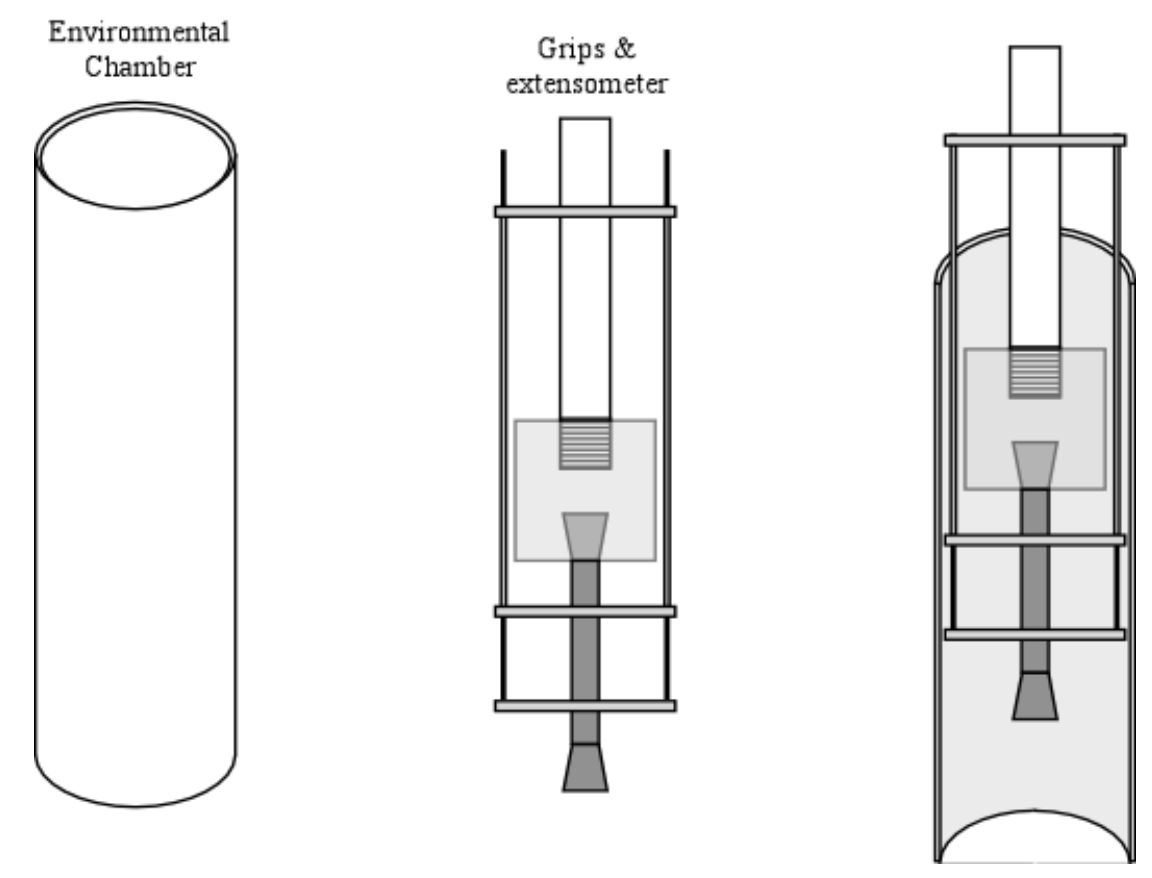

Figure 2. Schematic illustrations of a) environmental chamber surrounding sample and grip assembly b) high temperature grips and extensometers with sample, and c) grip assembly inside cut-away environmental chamber (retort). 


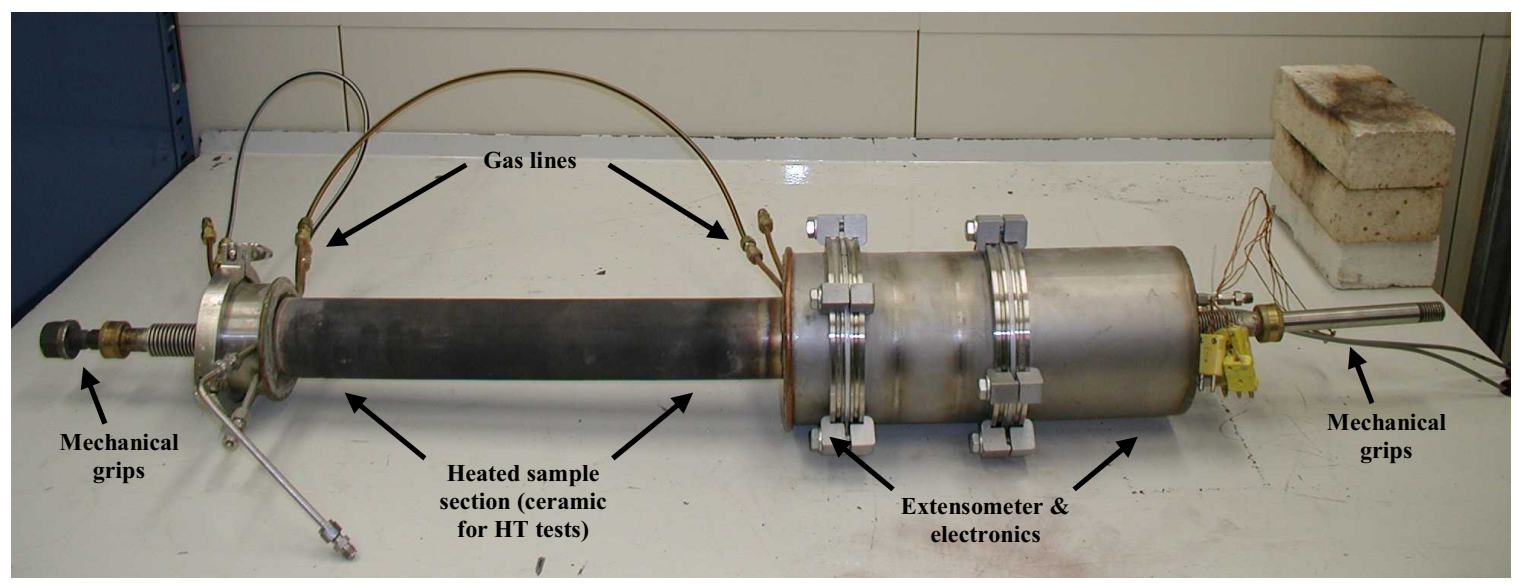

Figure 3. Typical environmental chamber housing required electronics, mechanical grips, and extensometers inside an Inconel chamber capable of withstanding test temperatures of $1000^{\circ} \mathrm{C}$.

High purity ceramic alumina environmental chambers will be required for the very high test temperatures (up to $1600^{\circ} \mathrm{C}$ ). The relatively small sample sizes for both the tubular and the flat plate specimens will be accommodated within the limited volume of the environmental chambers, see Figure 4. A high purity helium gas environment will be used within the chambers to simulate the VHTR reactor environment and preclude any potential oxidation degradation issues. High temperature tests and comparison studies on both composite types will begin next year.

High and room-temperature grip design: New thermally stable grips capable of being utilized for both cylindrical and flat-plate specimens were also addressed. These grips are designed to be used over the entire range of temperatures $\left(\mathrm{RT}-1600^{\circ} \mathrm{C}\right.$ ) and for all loads (tensile strength tests and low stress creep tests). At the expected high test temperatures actively loaded grips may not be possible even for shortterm tensile strength studies (i.e. mechanically tightened grips may creep and relax inside the environmental chamber). Therefore, the same loading system to be used for the long-term creep studies, a shoulder-mounted gripping system designed to allow passive gripping for high temperature testing, will be used for the elevated temperature geometry effects study. This will require the tensile specimens (both flat and tubular) to have a tapered end, or shoulder, fabricated on each end of the specimen.

High temperature grips capable of being used for both tubular and flat tensile specimens are currently being designed and fabricated. These are passive grips that use the flared ends of the test samples to load the specimens in tension, as opposed to active grips which are spring loaded and may lose their gripping force if exposed to high temperatures over longer periods of time, Figure 4. 


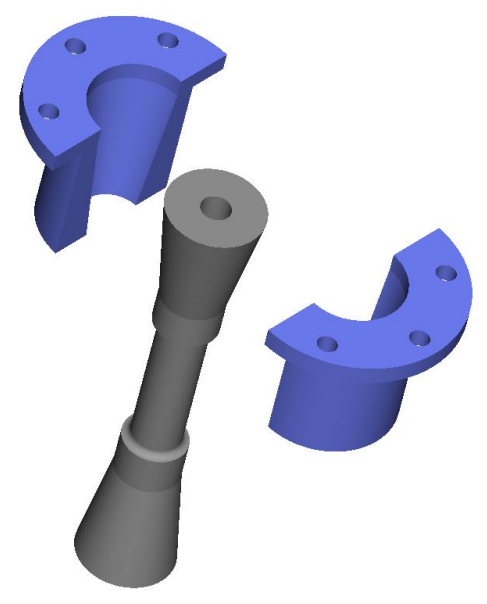

Error! Objects cannot be created from editing field codes.

Figure 4. High temperature grip design for passive loading of tubular test specimen.

The grips will be made from either graphite or silicon carbide for maximum thermal stability and strength. Over-sized components will reduce thermal and stress-related induced failures for high temperature tests.

\section{REFERENCES}

1. Y. Katoh, S.-G. Hong, L. L. Snead, E. Lara-Curzio, W. E. Windes, and C. H. Henager, Jr., "Summary of testing plans for failure mode assessment of composite tubes under stress," ORNL-GEN4/LTR-05002, July 30, 2005.

2. Y. Katoh, L. L. Snead, E. Lara-Curzio, W.E. Windes, and R. J. Shinavski, "Summary of SiC Tube Architecture and Fabrication,” ORNL-GEN4/LTR-05-07, 2005, August 30, 2005.

3. Yutai Katoh, L. L. Snead, E. Lara-Curzio, W.E. Windes, and R. J. Shinavski, "Summary of SiC Tube Architecture and Fabrication," ORNL report to be published, 2005, August 30, 2005.

4. J. Klett, W. Windes, and P. Lessing, "NGNP Composites Vendor Survey," ORNL/TM-2005/77, May $25,2005$.

5. Y. Katoh, S.-G. Hong, L. L. Snead, E. Lara-Curzio, W. E. Windes, and C. H. Henager, Jr., "Summary of testing plans for failure mode assessment of composite tubes under stress," ORNL-GEN4/LTR-05002, July 30, 2005. 